\title{
Rotational Stability of the Clareon Monofocal Aspheric Hydrophobic Acrylic Intraocular Lens 6 Months After Implantation
}

\author{
Thomas R Walters (D)', Robert Lehmann (D) ${ }^{2}$, Andrew Moyes ${ }^{3}$, John W French ${ }^{4}$, \\ Vidhyapriya Sreenivasan ${ }^{5}$, Satish S Modi ${ }^{6}$ \\ 'Texan Eye, Austin, TX, USA; ${ }^{2}$ Lehmann Eye Center, Nacogdoches, TX, USA; ${ }^{3}$ Moyes Eye Center, PC, Kansas City, MO, USA; ${ }^{4}$ Carolina Eye \\ Associates, Southern Pines, NC, USA; ${ }^{5}$ Alcon Vision LLC, Fort Worth, TX, USA; ${ }^{6}$ Seeta Eye Centers, Poughkeepsie, NY, USA \\ Correspondence: Thomas R Walters, Texan Eye, 1700 S MoPac Expy, Austin, TX, 78746, USA, Tel +I 5I2-327-7000, Email tom@nobhill.me
}

\begin{abstract}
Purpose: To determine the rotational stability of the Clareon ${ }^{\circledR}$ aspheric, monofocal, intraocular lens (IOL) up to 6 months after implantation. Methods: This prospective, single-arm clinical study evaluated rotational stability of the Clareon IOL in a subset of subjects ( $\mathrm{n}=141,6$ sites) that participated in an investigational device exemption trial for the Clareon IOL. The Clareon model (SY60CL) used in this subset was a non-toric IOL with toric axis markings to measure IOL rotation. All subjects (adults aged $\geq 22$ years who required cataract extraction by phacoemulsification) received the Clareon IOL unilaterally. The position of the toric markings was captured using dilated retroillumination slit-lamp photography and ocular anatomical landmarks. Post-operative rotational stability was assessed by an independent reading center. IOL rotation was defined as the difference between IOL axis of orientation on the day of surgery ( $\leq 1$ hour after surgery) and each post-operative visit. Post-operative IOL-based rotational stability was evaluated at day 0 (day of surgery), day 1 , week 1 , month 1 , and month 6 post-operatively.
\end{abstract}

Results: Compared with day 0 , mean absolute IOL rotation was $1.85^{\circ}$ on day $1(\mathrm{n}=127)$ and $2.27^{\circ}$ at month 6 ( $\left.\mathrm{n}=124\right)$. Absolute IOL rotation $\leq 5^{\circ}$ was observed in $95.3 \%$ of subjects on day 1 and $92.7 \%$ of subjects at month 6 , compared with day 0 . Between consecutive months 1 and 6 visits, mean absolute rotation was $<1^{\circ} ; 100 \%$ of subjects had $<10^{\circ}$ rotation and $98.4 \%$ had $\leq 5^{\circ}$. The range of rotation on day 1 was $0^{\circ}$ to $40.0^{\circ}$ because of a subject with ocular trauma; when the trauma-outlier was removed, the mean absolute IOL rotation was $1.6^{\circ}$ on day $1(\mathrm{n}=126)$ and $2.0^{\circ}$ at month $6(\mathrm{n}=123)$.

Conclusion: These results support the high rotational stability of the Clareon monofocal IOL and serve as reference of the rotational stability of Clareon toric IOLs.

Keywords: dilated retro-illuminated slit-lamp photography, ocular anatomical landmarks, post-operative intraocular lens rotation, toric markers

\section{Introduction}

Rotational stability is a critical factor for the success of toric intraocular lenses (IOLs) because of the impact of lens rotation on patient visual outcomes. Previous clinical studies have estimated that the cylinder position $1^{\circ}$ away from the intended axis may reduce toric power by approximately $3 \%$, rendering the intended refractive correction less effective and the patient outcome less predictable. ${ }^{1,2}$ IOL stability depends on the combination of lens design and materials. The lens must balance the ability to maintain its structure and location with a need to conform to a variety of ocular anatomies and biological challenges over time. ${ }^{3-7}$ The design elements known to impact postoperative IOL rotation include the material conformity (which affects the ease of positioning), the shape and tension of the haptics, the ability of the lens to adhere to the capsular bag, and the tendency of the lens to vault or remain in a planar position relative to the retina (and the axial pressure it would cause).

Based on findings from large cohort studies, the AcrySof toric IOL had lower levels of rotation compared with other hydrophobic acrylic lenses. ${ }^{8,9}$ The recently launched Clareon ${ }^{\circledR}$ IOL (toric model CNW0T2-T9; non-toric models 
CNA0T0 or SY60WF, depending on the delivery device) is equivalent in dimensions to the AcrySof IQ IOL (model SN60WF). Clareon and AcrySof IQ IOLs share the same haptic design, patented planar positioning within the capsular bag, and equivalent fibronectin properties that reduce posterior capsule opacification (PCO) and contribute to the stability of the lens. ${ }^{10,11}$ However, the Clareon IOL is made using a different polymer material with a slightly higher water content than the AcrySof IQ IOL. Furthermore, the Clareon IOL was designed with a modified proprietary edge curvature to reduce light scatter and edge glare onto the retina.

The mechanics and subsequent stability of the Clareon IOL were similar to those of AcrySof IQ in an in vitro analysis. ${ }^{10}$ The purpose of this study was to describe the post-operative rotational stability of the new Clareon IOL using objective image analysis performed by an independent reading center.

\section{Methods}

\section{Study Design}

This study assessed the rotational stability of the Clareon monofocal non-toric IOLs, which were manufactured with Alcon standard toric markings. A subset of 141 subjects from the investigational device exemption (IDE) trial for Clareon IOL was assessed at 6 sites. The full Clareon IDE trial was a prospective, multicenter, single-arm, unmasked clinical study in 350 subjects at 16 sites in the United States, conducted from July 2017 to February 2019. The IDE was approved by the FDA on 31 May 2017 and results were reported on ClinicalTrials.gov (NCT03170154).

Included in the study were adults aged $\geq 22$ years who required cataract extraction by phacoemulsification in at least 1 qualifying eye. Key exclusion criteria were disease or pathologic condition (other than cataract) expected to reduce potential postoperative best corrected distance visual acuity to worse than $0.30 \operatorname{logMAR}$, previous corneal surgery, rubella or traumatic cataract, ocular trauma or previous refractive surgery, and use of $\alpha_{1}$-antagonists that would require mechanical or surgical manipulation to enlarge the pupil. Subjects who required additional procedures because of intraoperative complications or any inability to place the IOL in the capsular bag owing to surgical complications were discontinued from the study during the surgery. There were no exclusion requirements based on corneal astigmatism; investigators used their discretion in excluding subjects with severe astigmatism.

Subjects attended a preoperative screening visit, an operative visit (day 0), and postoperative visits on day 1, week 1 , month 6, and month 12; unscheduled visits were conducted as needed. Dilated retro-illuminated slit-lamp photographs were captured for assessment of rotational stability at day 0 (approximately 1 hour after surgery), day 1 , week 1 , month 1 , and month 6 by certified photographers. Photographers at the 6 rotational-stability sites had to meet certification requirements before acquiring images for the study. Photographers were certified by an independent reading center if they demonstrated the ability to capture high-quality images of anatomical landmarks in clear, sharp focus and with appropriate illumination.

\section{Surgical Procedure}

The Clareon monofocal IOL is a 1-piece aspheric, hydrophobic, monofocal non-toric IOL made with UV- and blue lightfiltering acrylate/methacrylate copolymer. It has the same mechanical design as the AcrySof model SN60WF. ${ }^{10}$ Clareon IOL characteristics include STABLEFORCE ${ }^{\circledR}$ modified-L haptics (Alcon Vision), a full $6.0-\mathrm{mm}$ optic diameter, a proprietary square-edged design, and a 13.0-mm overall length. All IOLs implanted during the full IDE study were of spherical power (non-toric; all had toric axis markings located on the periphery of the optic at the haptic junctions, equivalent to those applied to AcrySof IQ toric) and were manufactured specifically for this investigation (Figure 1).

Surgeons used their preferred methodology to perform routine phacoemulsification to remove the cataract followed by unilateral implantation of the monofocal IOL. For subjects enrolled in the rotational stability substudy, preoperative manual limbus reference marks were typically placed at a combination of the 3-, 6-, 9-, and 12-o'clock positions, with the subject sitting upright at distance fixation to minimize cyclotorsion. Surgeons used their preferred method of axis marking to create the reference marks with violet dye. Although the Clareon IOLs were spherical, surgeons were instructed to place the IOLs on the axis of the steepest keratometric meridian or to default to 6- $\left(90^{\circ}\right)$ and $12-\mathrm{o}^{\prime}$ clock 


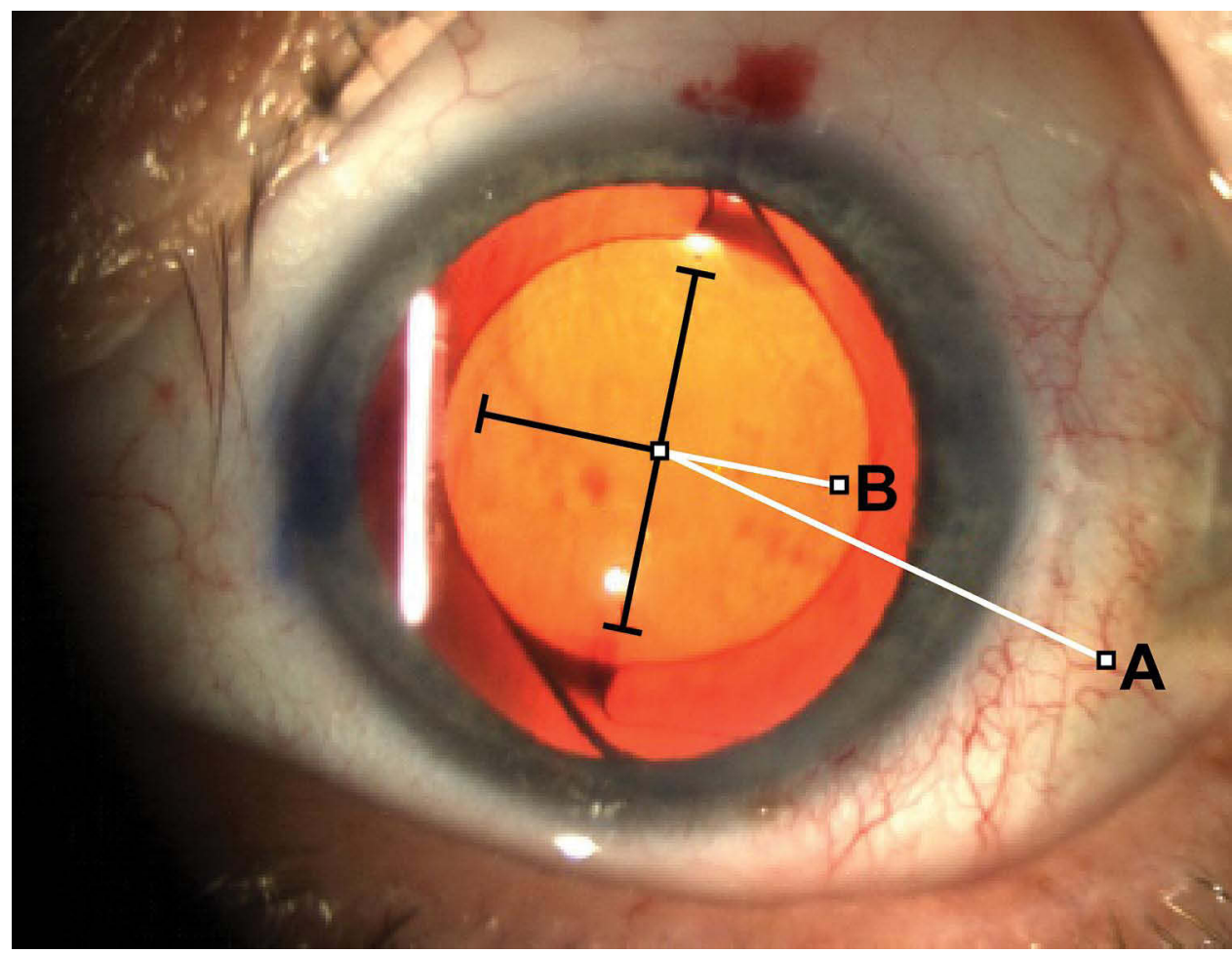

Figure I Slit-lamp photograph of the Clareon SY60CL non-toric monofocal IOL. A line was drawn from the pre-selected blood vessel to the intersection of the crosshair (A) and the closest orthogonal axis (B) to obtain the IOL axis of orientation. The IOL axis orientation angle between A and B was determined. IOL rotation over subsequent visits was defined as the difference between IOL axis of orientation at baseline (within I hour after surgery) and each post-operative visit. SY60CL was the designated lens model for clinical investigation; model number SY60WF is the Clareon lens that has been approved by the FDA.

Abbreviation: IOL, intraocular lens.

$\left(270^{\circ}\right)$ if the patient's keratometric readings were spherical. Pupils were dilated at the time of implantation to at least $7 \mathrm{~mm}$ to ensure that the IOL alignment markers could be well observed.

\section{Evaluation and Analysis of Rotational Stability}

Using the toric axis IOL markings, the axis position of the Clareon IOL was assessed with dilated slit-lamp photography and retro-illumination approximately within 1 hour after surgery on day 0 . A certified photographer captured similar dilated slitlamp images at the follow-up visits on day 1 , week 1, month 1, and month 6. Images were sent to an independent reading center to determine the IOL axis position at each visit. The reading center graders were masked to subject name, initials, and date of birth, as well as investigator site identifiers and reason for exam. The grader recorded the confidence score on images collected at each time point to ensure adequate image quality with sufficient dilation for visibility of toric markers, presence of reliable blood vessel, direct fixation, and clear image focus. The grader then compared the images across all visits for a subject and identified a blood vessel marker which was clearly visible at each visit and appeared in the same location. For each image, a crosshair tool was populated using the toric markers as a reference. A line was drawn from the pre-selected blood vessel to the intersection of the crosshair and the closest orthogonal axis (Figure 1) to obtain the IOL axis of orientation. Post-operative IOL rotation was defined as the difference between IOL axis of orientation immediately after surgery on day 0 and each postoperative visit. This method of estimating IOL rotation demonstrated good repeatability ( $\mathrm{SD} \pm 0.31^{\circ}$ ) across 3 repeat analyses performed over 3 days (to minimize potential for memorization).

Results were compared with performance targets for rotational stability in EN ISO 11979-7:2014 IOL which state that axis orientation compared between the day of surgery and month 6 should be $<10^{\circ}$ in $90 \%$ of eyes; $<20^{\circ}$ in $95 \%$ of eyes, and $<30^{\circ}$ in $99 \%$ of eyes. ${ }^{12}$ Additionally, rotational stability of the Clareon IOL was assessed between 2 consecutive visits (month 1 and month 6) in accordance with American National Standards Institute (ANSI) standard for toric IOL (Z80.30, 2010) which states that IOL stability is achieved if $90 \%$ of the eyes rotate $\leq 5^{\circ}$ between the 2 consecutive visits, at least 3 months apart. ${ }^{13}$ 


\section{Ethics}

This study was conducted in accordance with the principles of the Declaration of Helsinki and in compliance with Good Clinical Practice and the code of federal regulation. The study protocol was approved by the Sterling Institutional Review Board (6300 Powers Ferry Rd, Suite 600-351, Atlanta, GA 30339). Subjects provided voluntary written informed consent before any screening or trial-related procedures.

\section{Results}

\section{Subjects}

Of the 141 subjects at 6 sites in the United States who received the Clareon IOL as part of a substudy evaluating rotational stability, 10 subjects had images on day 0 that were ungradable because of several factors, including poor image focus, unreliable blood vessel marker, insufficient eyelid retraction, or small pupil size.

Demographics and baseline characteristics of the study subset are summarized in Table 1. Subjects had a mean \pm SD age of $70.0 \pm 6.7$ years. Sixty-three percent of the subjects were female and $92 \%$ were white. Mean \pm SD astigmatism at baseline was $0.68 \pm 0.43 \mathrm{D}$, with a range of $0.0-2.10$.

Table I Subject Demographics and Baseline Characteristics (Rotation Analysis Set)

\begin{tabular}{|c|c|}
\hline Parameter & SY60CL IOL $(n=|4|)$ \\
\hline \multicolumn{2}{|l|}{ Age, years } \\
\hline Mean \pm SD & $70.0 \pm 6.68$ \\
\hline Range & $53-86$ \\
\hline \multicolumn{2}{|l|}{ Age group, n (\%) } \\
\hline$<65$ & $25(18)$ \\
\hline$\geq 65$ & $116(82)$ \\
\hline \multicolumn{2}{|l|}{ Sex, n (\%) } \\
\hline Female & $89(63)$ \\
\hline Male & $52(37)$ \\
\hline \multicolumn{2}{|l|}{ Race, n (\%) } \\
\hline White & $129(92)$ \\
\hline Black or African American & II (8) \\
\hline Asian & I (0.7) \\
\hline \multicolumn{2}{|l|}{ Monocular BCDVA, logMAR } \\
\hline Mean \pm SD & $0.20 I \pm 0.200$ \\
\hline Range & $-0.18-1.70$ \\
\hline \multicolumn{2}{|l|}{ Axial length } \\
\hline Mean \pm SD & $24.0 \pm 1.0$ \\
\hline Range & $21.3-26.6$ \\
\hline \multicolumn{2}{|l|}{ Axial length category, n (\%) } \\
\hline Short $(<21 \mathrm{~mm})$ & 0 \\
\hline Medium $(2 \mathrm{I}-26 \mathrm{~mm})$ & $138(98)$ \\
\hline Long (>26 mm) & $3(2)$ \\
\hline \multicolumn{2}{|l|}{ Corneal astigmatism, D } \\
\hline Mean \pm SD & $0.676 \pm 0.428$ \\
\hline Range & $0.0-2.10$ \\
\hline \multicolumn{2}{|c|}{ Intended axis of placement, degrees } \\
\hline Mean \pm SD & $98.5 \pm 50.2$ \\
\hline Range & $2.0-180.0$ \\
\hline
\end{tabular}

Abbreviations: BCDVA, best corrected distance visual acuity; IOL, intraocular lens. 


\section{Post-Operative Rotational Stability}

In the full rotation dataset, mean absolute IOL rotation compared with the day of surgery was $1.85^{\circ}$ on day 1 (Figure 2A; 95\% CI, $1.19^{\circ}-2.50^{\circ}$; median, $0.94^{\circ}$; range, $0.0^{\circ}-38.2^{\circ}$ ). At month 6 , mean absolute IOL rotation compared with the day of surgery was $2.27^{\circ}\left(95 \% \mathrm{CI}, 1.58^{\circ}-2.96^{\circ}\right.$; median, $1.45^{\circ}$; range, $\left.0.01^{\circ}-40.0^{\circ}\right)$. Absolute IOL rotation $\leq 5^{\circ}$ was observed in $95.3 \%$ (121/127) of subjects on day 1 and in 92.7\% (115/124) of subjects at month 6 (Figure 2B). Absolute IOL rotation $\leq 10^{\circ}$ was observed in $98.4 \%$ of subjects on day $1(125 / 127)$ and month $6(122 / 124)$.

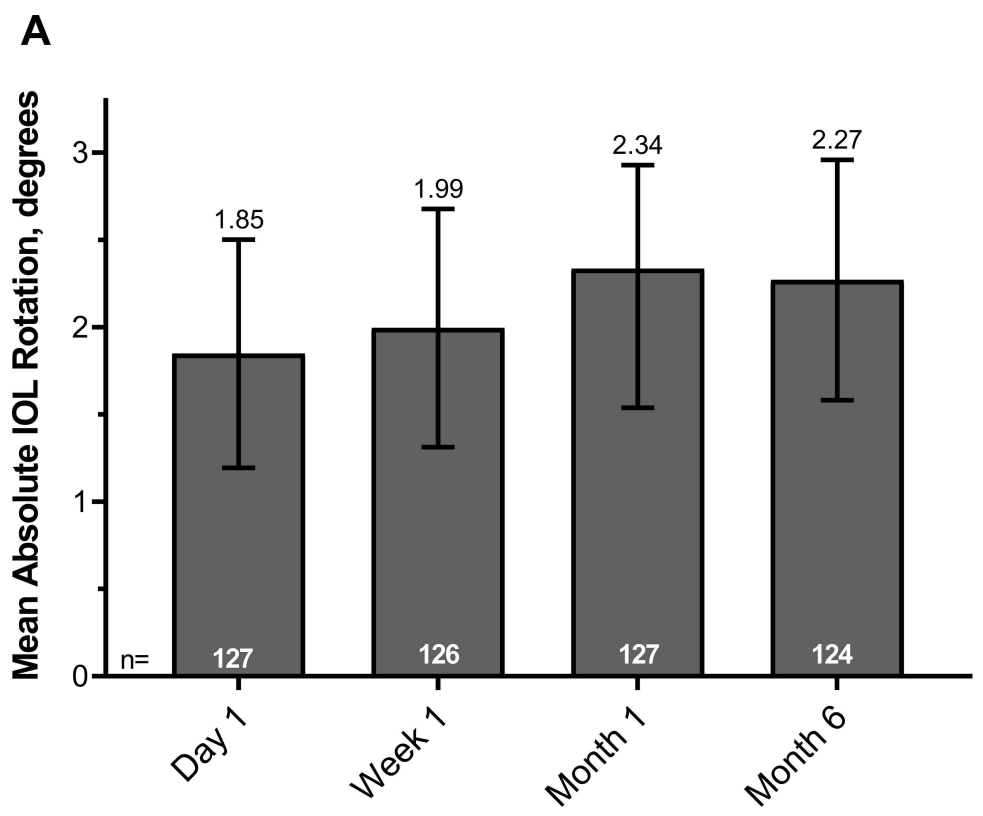

B

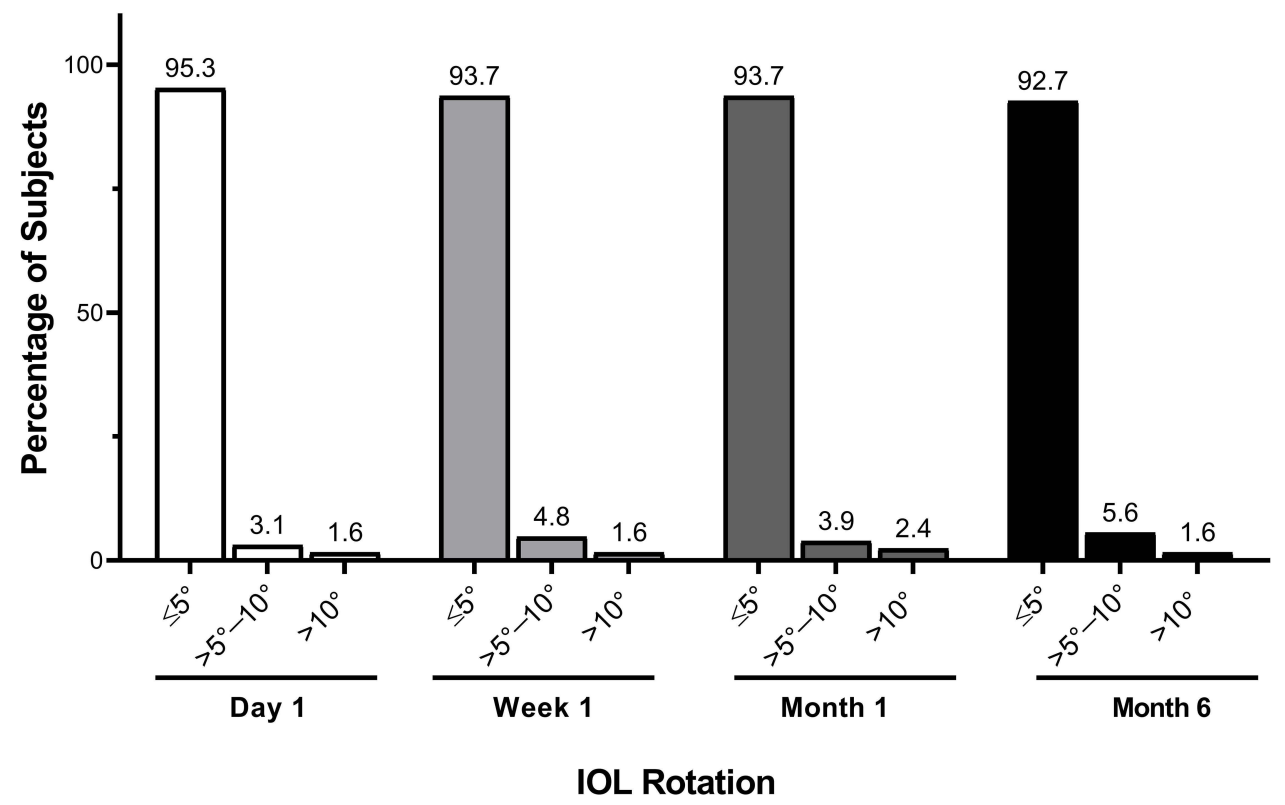

Figure 2 Mean absolute IOL rotation compared with day of surgery $(\mathbf{A})$ and distribution of absolute IOL rotation over time (B) in subjects who received the Clareon IOL $(n=|4|)$. Error bars represent $95 \% \mathrm{Cls}$. These data included an outlier-subject with ocular trauma. Abbreviation: IOL, intraocular lens. 
IOL rotational stability assessed between consecutive visits in accordance with ANSI Z80.30 2010 showed mean absolute rotation $<1^{\circ}\left(0.97^{\circ} \pm 1.0^{\circ}\right)$ between months 1 and 6 following implantation; 98.4\% (127/129) of subjects had $\leq 5^{\circ}$ rotation (Figure 3) and $100 \%$ of subjects had $<10^{\circ}$ rotation between months 1 and $6(n=129)$.

Although mean IOL rotation observed in this study was small, the range $\left(0^{\circ}-40^{\circ}\right)$ indicated the presence of outliers. Post-operative IOL rotation $>10^{\circ}$ was observed in 1 subject after day 1 . The subject had experienced an ocular trauma shortly after discharge, noted by the surgeon as the cause for the IOL decentration and rotation of $38.2^{\circ}$ at day 1 and $40.0^{\circ}$ at month 6 . To describe the normal stability of the Clareon IOL, we performed a sub-analysis to exclude the subject with ocular trauma. After the outlier was removed from analysis, mean absolute IOL rotation was $1.56^{\circ}$ on day $1(\mathrm{n}=126)$ and $1.96^{\circ}$ at month $6(\mathrm{n}=123$; Figure $4 \mathrm{~A})$. Overall, $96.0 \%$ of subjects had $\leq 5^{\circ}$ absolute IOL rotation from day 0 to day 1 $(\mathrm{n}=121) ; 93.5 \%$ of subjects had $\leq 5^{\circ}$ absolute rotation from day 0 to month $6(\mathrm{n}=115)$; and $98.4 \%$ of subjects had $\leq 5^{\circ}$ rotation between months 1 and $6 \mathrm{n}=128$; Figure 4B). All subjects (100\%) had $\leq 10^{\circ}$ rotation between months 1 and 6 .

\section{Discussion}

Post-operative IOL rotational stability is a key factor in the success of toric visual correction. Rotation of toric IOLs can result in a deterioration of the quality of the retinal image and subsequent reduction in visual function. ${ }^{1,14,15}$ When the subject with ocular trauma was included in the analysis, this study found that $95.3 \%$ of subjects receiving the Clareon IOL experienced $\leq 5^{\circ}$ rotation at day 1 compared with baseline. Between months 1 and 6 after implantation, most subjects $(126 / 128 ; 98.4 \%)$ had $\leq 5^{\circ}$ rotation and all subjects had $<10^{\circ}$ rotation, supporting the long-term rotational stability of the Clareon IOL. One subject was an outlier because of ocular trauma. When the outlier was excluded from analysis, $96.0 \%$ of subjects experienced $\leq 5^{\circ}$ rotation at day 1 compared with baseline. Mean absolute IOL rotation was $1.56^{\circ}$ at day 1 and $1.96^{\circ}$ at month 6 .

Historically, clinical trials assessing IOLs have followed the prescribed standards and did not include measures of post-operative rotation immediately after surgery. In this study, the majority of rotation was observed at day 0

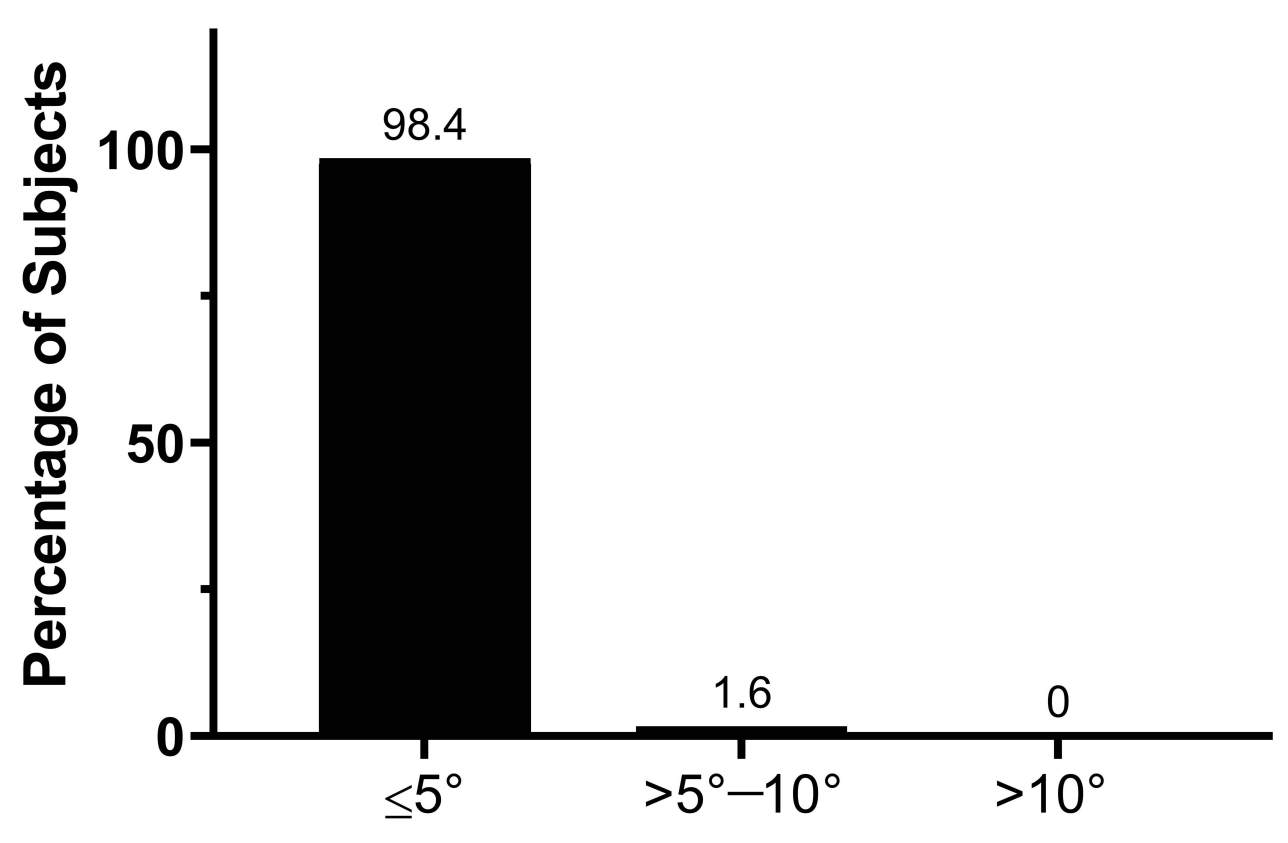

\section{Change in Absolute IOL Rotation Between Months 1 and 6}

Figure 3 Consecutive post-operative rotational stability. Absolute change in IOL axis between months I and $6(n=\mid 29)$. Abbreviation: IOL, intraocular lens. 


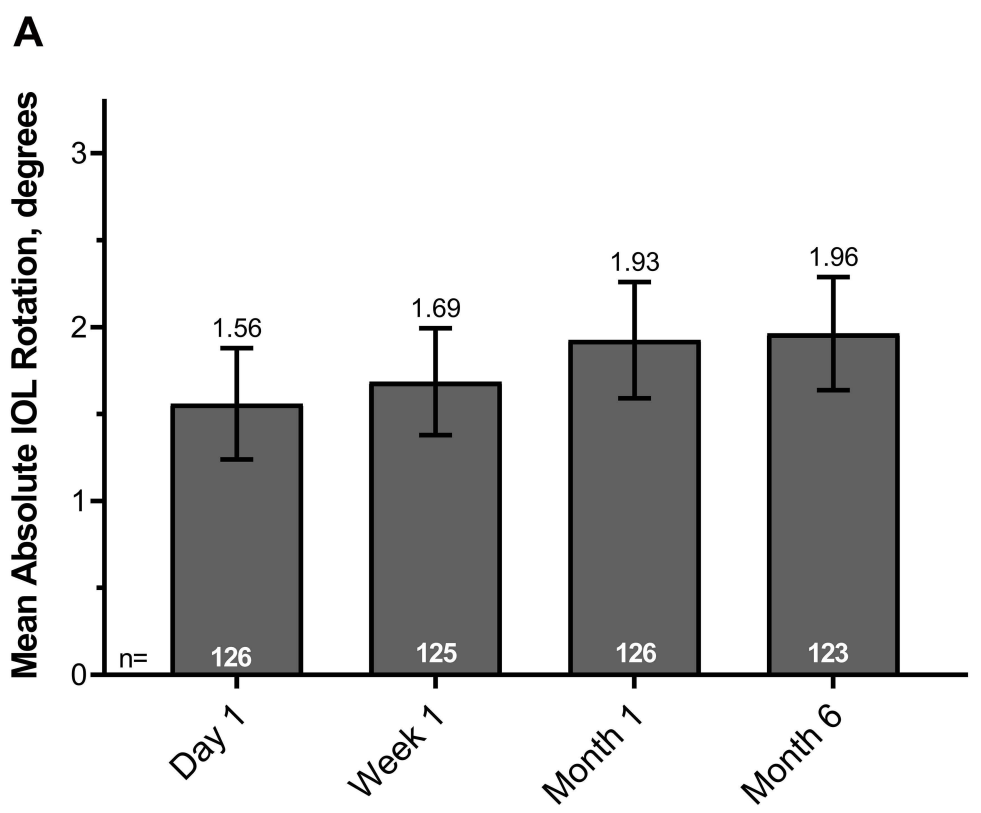

B

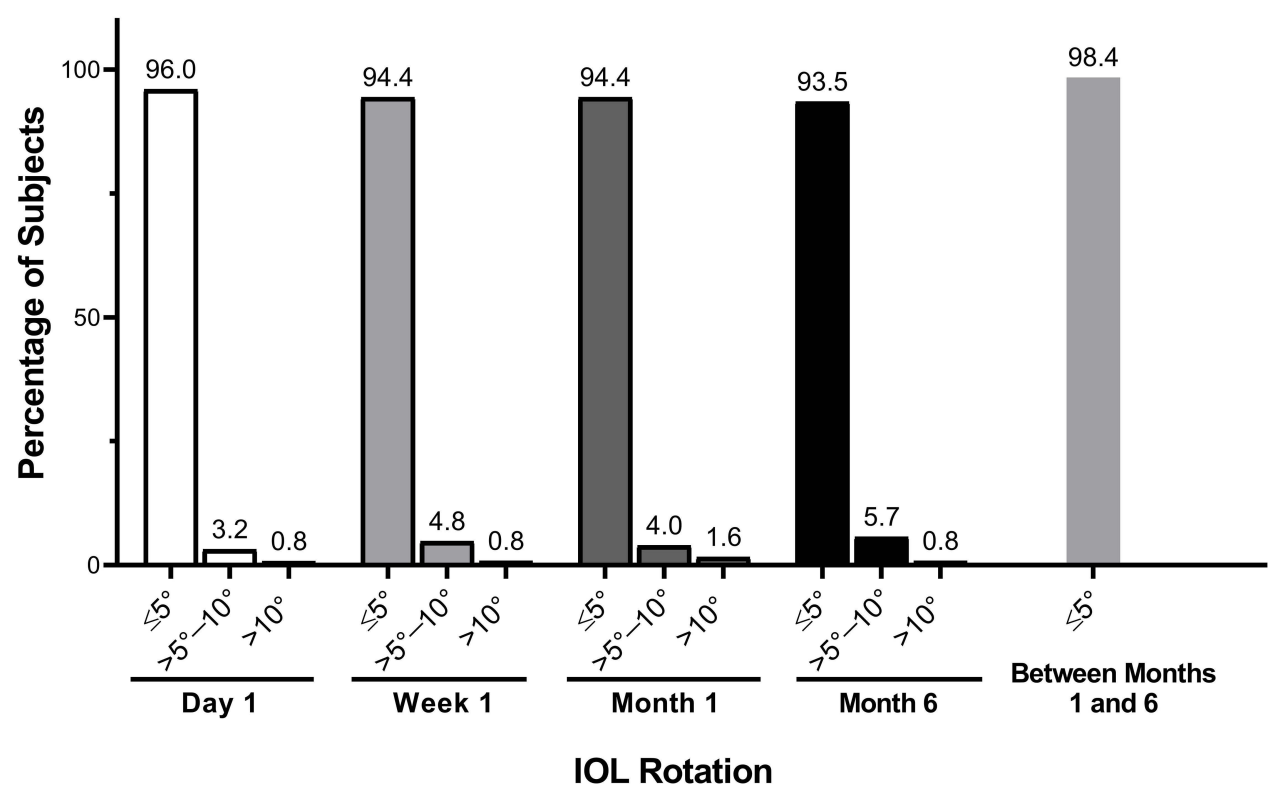

Figure 4 Subset analysis excluding the subject with $>10^{\circ}$ rotation because of ocular trauma. Mean absolute $\mathrm{OL}$ rotation compared with day of surgery (A) and distribution of absolute IOL rotation over time $(B)$ in subjects who received the Clareon IOL excluding the outlier $(n=140)$. Error bars represent $95 \%$ Cls.

Abbreviation: IOL, intraocular lens.

(approximately within 1 hour after surgery) and day 1. This is in agreement with recent findings demonstrating that the first hours and days after implantation are the most important for IOL rotation across all hydrophobic lenses. ${ }^{8,16,17}$

The method of evaluation of IOL position over time is a significant factor in accurate assessment of rotational stability. Slit-lamp-based measures of IOL rotational stability are highly variable because of the inherent subjectivity of assessment, variable cyclotorsion effects, potential inconsistencies, and lack of reproducibility in selecting anatomical reference structures. To improve the assessment of IOL rotation, this study obtained dilated retro-illuminated slit-lamp images and an independent grading center used consistent ocular anatomical landmarks to increase objectivity and 
accuracy of rotational measures using image analysis. While several slit-lamp and photographic methods exist to assess rotation stability, ${ }^{8,17,18}$ precision is critical to ensure increased signal to noise ratio. The image processing technique used in this study showed good repeatability (SD within $0.31^{\circ}$ ), consistent with other studies that showed less variability in rotational stability when using objective methods versus slit-lamp evaluation. ${ }^{18}$

As image-guided or digital marking systems become more common, intraoperative IOL positioning is expected to improve; furthermore, advances in baseline recording and follow-up may lead to more accurate toric IOL monitoring. Future studies will be needed to assess IOL rotational stability for the Clareon toric IOL and other toric IOL models, as well as effects of rotational stability on visual outcomes in subjects with astigmatism. Limitations of this study included a single arm design and possible variation in placement of reference axis markers because surgeons could use their preferred system to mark the cornea.

\section{Conclusions}

The results of this study support the long-term rotational stability of the Clareon IOL. There was minimal absolute mean IOL rotation between day $1\left(1.85^{\circ}\right)$ and month $6\left(2.27^{\circ}\right)$ post-implantation compared with the day of surgery (ocular trauma outlier included). Based on previous studies, this level of rotation is expected to have a negligible impact on patient outcomes. ${ }^{15,19}$ Six months after surgery, nearly all subjects $\left(122 / 124 ; 98.4 \%\right.$ ) had $\leq 10^{\circ}$ rotation, and $100 \%$ of subjects had $<10^{\circ}$ rotation between months 1 and 6 . These results demonstrate the high rotational stability of the Clareon monofocal IOL, support greater stability of the Clareon IOL compared with the AcrySof IQ toric IOL at similar time points in other studies, ${ }^{7,8}$ and serve as a reference for the rotational stability of Clareon toric IOLs.

\section{Abbreviations}

ANSI, American National Standards Institute; BCDVA, best corrected distance visual acuity; IDE, investigational device exemption; IOL, intraocular lens; PCO, posterior capsule opacification.

\section{Data Sharing Statement}

The data used to support the primary findings of this study are available at clinicaltrials.gov (NCT03170154).

\section{Acknowledgments}

The authors would like to thank Dr. Allison Rand for contributing to this study. The authors would also like to thank Dr. Aldo Martinez and Dr. Rachael Peterson for their contribution to the preparation of the manuscript and thorough review. Medical writing assistance was provided by Natalia Zhukovskaya, PhD, of ICON (North Wales, PA), and was funded by Alcon.

\section{Funding}

This study was funded by Alcon Vision LLC. Alcon assisted with the design and conduct of the study; collection, management, analysis, and interpretation of the data; and preparation, review, and approval of the manuscript.

\section{Disclosure}

RL and SSM are consultants for Alcon. VS is an employee of Alcon. The authors report no other conflicts of interest in this work.

\section{References}

1. Tognetto D, Perrotta AA, Bauci F, et al. Quality of images with toric intraocular lenses. J Cataract Refract Surg. 2018;44(3):376-381. doi:10.1016/j. jers.2017.10.053

2. Shimizu K, Misawa A, Suzuki Y. Toric intraocular lenses: correcting astigmatism while controlling axis shift. J Cataract Refract Surg. 1994;20 (5):523-526.

3. Li S, Li X, He S, et al. Early postoperative rotational stability and its related factors of a single-piece acrylic toric intraocular lens. Eye (Lond). 2020;34(3):474-479. 
4. Zhu X, He W, Zhang K, Lu Y. Factors influencing 1-year rotational stability of AcrySof toric intraocular lenses. Br J Ophthalmol. 2016;100 (2):263-268.

5. Maedel S, Hirnschall N, Chen YA, Findl O. Rotational performance and corneal astigmatism correction during cataract surgery: aspheric toric intraocular lens versus aspheric nontoric intraocular lens with opposite clear corneal incision. J Cataract Refract Surg. 2014;40(8):1355-1362.

6. Vandekerckhove K. Rotational stability of monofocal and trifocal intraocular toric lenses with identical design and material but different surface treatment. J Refract Surg. 2018;34(2):84-91.

7. Chang DF. Comparative rotational stability of single-piece open-loop acrylic and plate-haptic silicone toric intraocular lenses. $J$ Cataract Refract Surg. 2008;34(11):1842-1847.

8. Lee BS, Chang DF. Comparison of the rotational stability of two toric intraocular lenses in 1273 consecutive eyes. Ophthalmology. $2018 ; 125$ (9):1325-1331.

9. Kramer BA, Hardten DR, Berdahl JP. Rotation characteristics of three toric monofocal intraocular lenses. Clin Ophthalmol. $2020 ; 14: 4379-4384$.

10. Lane S, Collins S, Das KK, et al. Evaluation of intraocular lens mechanical stability. J Cataract Refract Surg. 2019;45(4):501-506. doi:10.1016/j. jers.2018.10.043

11. Lehmann R, Maxwell A, Lubeck DM, et al. Effectiveness and safety of the Clareon monofocal intraocular lens: outcomes from a 12-month singlearm clinical study in a large sample. Clin Ophthalmol. 2021;15:1647-1657.

12. ISO 11979-7:2018. Ophthalmic implants - intraocular lenses - part 7: clinical investigations of intraocular lenses for the correction of aphakia; July $19,2018$.

13. American National Standard for Ophthalmics - Accommodative Intraocular Lenses; ANSI Z80.30-2010. American National Standards Institute, Inc.; 2010.

14. Nemeth G. One degree of misalignment does not lead to a 3.3\% effect decrease after implantation of a toric intraocular lens. $J$ Cataract Refract Surg. 2020;46(3):482.

15. Felipe A, Artigas JM, Diez-Ajenjo A, Garcia-Domene C, Alcocer P. Residual astigmatism produced by toric intraocular lens rotation. J Cataract Refract Surg. 2011;37(10):1895-1901.

16. Inoue Y, Takehara H, Oshika T. Axis misalignment of toric intraocular lens: placement error and postoperative rotation. Ophthalmology. 2017;124 (9):1424-1425.

17. Schartmuller D, Schriefl S, Schwarzenbacher L, Leydolt C, Menapace R. True rotational stability of a single-piece hydrophobic intraocular lens. Br J Ophthalmol. 2019;103(2):186-190.

18. Sandoval HP, Lane S, Slade S, et al. Evaluating rotational stability of an extended depth of focus toric intraocular lens using a slit lamp and imagebased analysis. Clin Ophthalmol. 2020;14:2405-2410.

19. Bachernegg A, Ruckl T, Riha W, Grabner G, Dexl AK. Rotational stability and visual outcome after implantation of a new toric intraocular lens for the correction of corneal astigmatism during cataract surgery. J Cataract Refract Surg. 2013;39(9):1390-1398.

Clinical Ophthalmology

Dovepress

\section{Publish your work in this journal}

Clinical Ophthalmology is an international, peer-reviewed journal covering all subspecialties within ophthalmology. Key topics include: Optometry; Visual science; Pharmacology and drug therapy in eye diseases; Basic Sciences; Primary and Secondary eye care; Patient Safety and Quality of Care Improvements. This journal is indexed on PubMed Central and CAS, and is the official journal of The Society of Clinical Ophthalmology (SCO). The manuscript management system is completely online and includes a very quick and fair peer-review system, which is all easy to use. Visit http://www. dovepress.com/testimonials.php to read real quotes from published authors.

Submit your manuscript here: https://www.dovepress.com/clinical-ophthalmology-journal 